\title{
Volatiles from potato plants infected with potato leafroll virus attract and arrest the virus vector, Myzus persicae (Homoptera: Aphididae)
}

\author{
Sanford D. Eigenbrode ${ }^{1^{*}}$, Hongjian Ding ${ }^{1}$, Patrick Shiel $^{2}$ \\ and Philip H. Berger ${ }^{2}$
}

${ }^{1}$ Division of Entomology, and ${ }^{2}$ Division of Plant Pathology, Department of Plant, Soil and Entomological Sciences, University of Idaho, Moscow, ID 83844-2339, USA

\begin{abstract}
The influence of viral disease symptoms on the behaviour of virus vectors has implications for disease epidemiology. Here we show that previously reported preferential colonization of potatoes infected by potato leafroll virus (genus Polerovirus) (luteovirus) (PLRV) by alatae of Myzus persicae, the principal aphid vector of PLRV, is influenced by volatile emissions from PLRV-infected plants. First, in our bioassays both differential immigration and emigration were involved in preferential colonization by aphids of PLRV-infected plants. Second, $M$. persicae apterae aggregated preferentially, on screening above leaflets of PLRV-infected potatoes as compared with leaflets from uninfected plants, or from plants infected with potato virus X (PVX) or potato virus Y (PVY). Third, the aphids aggregated preferentially on screening over leaflet models treated with volatiles collected from PLRV-infected plants as compared with those collected from uninfected plants. The specific cues eliciting the aphid responses were not determined, but differences between headspace volatiles of infected and uninfected plants suggest possible ones.
\end{abstract}

Keywords: plant viruses; volatiles; insect vectors; potatoes; green peach aphid

\section{INTRODUCTION}

Virus-infected plants undergo changes that affect the biology of insect vectors of plant viruses. Insect vectors feeding on infected plants have been reported to differ in growth rates, longevity and fecundity, as compared with those on uninfected plants (Kennedy 1951; Baker 1960; Hodgson 1981; Costa et al. 1991; Fereres et al. 1999). Some insect vectors preferentially colonize infected plants that are superior hosts to uninfected plants (Macias \& Mink 1969; Ajayi \& Dewar 1983; Eckel \& Lampert 1996; Castle et al. 1998) or avoid infected plants that are inferior hosts (Blua \& Perring 1992). Vector responses to virusinfected plants may be advantageous for the virus by promoting its spread (Blua \& Perring 1992; McElhany et al. 1995). Discovering the mechanisms mediating such interactions is fundamental to understanding their ecology and evolution.

Preferential colonization of virus-infected plants by aphids has been attributed to the yellowing of infected tissues, which become more visually attractive to aphids (Macias \& Mink 1969; Eckel \& Lampert 1996), and may involve aphid behavioural responses to virus-induced changes in plant quality. As yet unexamined in this context are plant volatiles, which can affect aphid behaviour (Nottingham et al. 1991; Pickett et al. 1992). In this paper, we examine the effects of plant volatiles from virusinfected plants on the behaviour of an aphid virus vector.

The aphid Myzus persicae (Sulzer) grows faster, has higher fecundity and preferentially settles on cultivated potato, Solanum tuberosum L., infected by the potato leaf-

*Author for correspondence (sanforde@uidaho.edu). roll virus (genus Polerovirus) (luteovirus) (PLRV) than on uninfected potato plants (Castle \& Berger 1993; Castle et al. 1998). By contrast, plants infected by potato virus $\mathrm{Y}$ (PVY) or potato virus X (PVX) are neither better hosts nor are they preferentially colonized by $M$. persicae (Castle \& Berger 1993; Castle et al. 1998). Myzus persicae is the principal vector of PLRV and acquires the virus in a persistent manner, in which PLRV particles are associated with the salivary glands of the aphid after acquisition (Harrison 1984). PVY is a non-circulative virus transmitted in a non-persistent manner by several aphid species (de Bokx \& Huttinga 1981). PVX does not require a vector and typically is transmitted mechanically.

Our overall objective was to determine if volatile cues influence the response of $M$. persicae to PLRV-infected potato plants. Our specific objectives were (i) to verify the preference of $M$. persicae for PLRV-infected potatoes versus virus-free, PVX- or PVY-infected potatoes, (ii) to determine if this preference is detectable within a timeframe consistent with a behavioural response to plant cues, (iii) to determine, by observation, the relative importance of immigration and emigration rates in determining aphid response, (iv) to determine if contact or volatile cues mediate aphid responses, and (v) to identify possible volatile components influencing aphid response.

\section{MATERIAL AND METHODS}

\section{(a) Insects}

The aphid colony originated from the 'OUR' clone (obtained from T. Mowry, University of Idaho, Parma, Idaho) and was maintained on seedlings of Brassica juncea L. cv. 'Florida Broadleaf'. The behaviour of both alate (winged) and apterous (wingless) nymphs could be affected by cues from virus-infected 
plants, with implications for virus spread. In these experiments we tested 2-3-instar apterous aphids from this colony because there is considerable interplant movement by these nymphs in the field and laboratory (personal observations).

\section{(b) Plants}

Certified virus-free explants of cv. Russet Burbank potato were obtained from the University of Idaho Potato Nuclear Seed Program. Virus-free explants were propagated in tissue culture at $20^{\circ} \mathrm{C}, 18 \mathrm{~L}: 6 \mathrm{D}$. Rooted explants were planted in clean $6 \mathrm{~cm}$ pots filled with Sunshine Mix \#1 potting mixture (SunGro Horticulture, Bellevue, WA). The plants were then grown in the greenhouse at $20 \pm 2{ }^{\circ} \mathrm{C}$ with supplementary lighting to achieve an $18 \mathrm{~h}$ daylength.

\section{(c) Inoculation}

After three weeks, three plants were assigned to each treatment (PVX-infected, PVY-infected, PLRV-infected, uninfected) and allowed to grow for an additional week, after which plants in the infected treatments were inoculated. Inocula for PVX and PVY were prepared by grinding leaf tissue from PVX- or PVYinfected Russet Burbank potato in a $1: 5$ dilution of $0.05 \mathrm{M}$ sodium phosphate buffer, $\mathrm{pH} 7.0$, with $0.02 \mathrm{M}$ of sodium sulphite. PVX and PVY inocula were rubbed onto carborundum (400 mesh)-dusted leaves of the treated plants with a cotton swab. Control plants were inoculated with buffer only. After one week, the virus-inoculated and control plants were repotted into $15 \mathrm{~cm}$ diameter pots.

PLRV-infected plants were prepared by exposing them to viruliferous aphids. Virus-free $M$. persicae were placed in the dish and allowed to feed for 2-3 days on PLRV-infected leaflets. Five to ten of these aphids were then placed on an uninfected plant and allowed to feed for 3-4 days. Aphids were removed and the inoculated plants were repotted into $15 \mathrm{~cm}$ diameter clean pots.

After infection was confirmed based on symptoms, plants from all treatments were propagated from cuttings four weeks before the experiments. Propagation from cuttings eliminates cues that might be left by the infecting aphids and reduces possible physiological effects of aphid feeding on the plants (Campbell et al. 1993). As an additional check for aphidfeeding-induced changes in the plants, we produced shaminoculated plants using aviruliferous $M$. persicae but otherwise following the procedures used for PLRV infection.

\section{(d) Aphid response to virus-infected and virus-free potato leaflets}

Approximately 100 2-3-instar apterous $M$. persicae were placed in a darkened bioassay arena. The arena for this and subsequent tests was darkened to eliminate visual cues that could influence aphid behaviour. The aphids exhibit negative geotaxis in a darkened arena. In the bioassay they ascended a vertical glass rod $(0.5 \mathrm{~cm}$ diameter $\times 5 \mathrm{~cm}$ in height $)$ to a horizontal $2 \mathrm{~cm}$ diameter circular polyethylene platform, which was in contact with four leaflets equally spaced around and contacting the platform. The leaflets were attached to the test plants during the bioassays and two leaflets from each of two treatments were used to produce a dual choice test. Aphid locations were recorded $1 \mathrm{~h}$ after initiation of the bioassay. There were 6-7 replicates for each of three comparisons: PLRV-infected versus uninfected control, PLRV-infected versus PVY-infected, PLRV-infected versus PVX-infected. Each comparison was analysed as a separate experiment comparing the number of aphids on each treatment using a generalized linear model assuming a binomial distribution with a logit link function (PROC GENMOD in SAS, SAS Institute, Cary, NC). Aphids not located on either treatment were excluded from this analysis.

\section{(e) Aphid movements between PLRV-infected versus uninfected leaflets}

In a separate experiment, aphids were observed continuously for $1 \mathrm{~h}$ in the arena using a video system with red light for illumination. The number of aphids observed moving onto and off the PLRV-infected and uninfected leaflets was recorded. From these data we calculated the average number of aphids immigrating into each treatment per $10 \mathrm{~min}$, the average number of aphids emigrating from each treatment per $10 \mathrm{~min}$, the average percentage of aphids emigrating from each treatment $(100 \times$ number emigrating/number immigrating) per $10 \mathrm{~min}$, and the average net arrestment of aphids on each treatment per $10 \mathrm{~min}$ (number immigrating - number emigrating). Each of these measures of aphid response was compared using a generalized linear model assuming a Poisson distribution with a log link function (PROC GENMOD in SAS). The experiment included four replicate $1 \mathrm{~h}$ observations.

\section{(f) Aphid response to headspace above virus- infected and virus-free leaflets}

An arena made from a polystyrene $150 \mathrm{~mm}$ diameter Petri dish was fitted with a false floor of polyethylene screening (mesh size $c a .1 \mathrm{~mm}$ ) on which the aphids could walk freely. Two leaflets, still attached to plants, were positioned opposite one another and $c a .4 \mathrm{~mm}$ beneath the screen floor. Aphids on the screening could not touch the leaflets with their stylets or tarsi. This distance was chosen to expose the aphids to volatiles near the plants (headspace volatiles) in the absence of visual, gustatory, or contact cues. This close distance was also used to minimize the potential confounding influence of volatile cues from the two treatments mixing within the arena. To further minimize this, the space above the test screening was large enough (volume $=750 \mathrm{~cm}^{2}$ ) to prevent saturation with plant volatiles from two treatments during the test. Fifty aphids were placed in the darkened arena, equidistant from the treated leaves. Thereafter, aphid locations were recorded every $10 \mathrm{~min}$ for $1 \mathrm{~h}$. During an observation, the arena was opened and illuminated for $c a .20 \mathrm{~s}$. An aphid was recorded as responding to a leaflet if it was directly above any part of the leaflet. The comparisons tested were the same as those for aphids in contact with the leaflets. For each comparison, there were $4-6$ replications. The mean number of aphids on each of the two treatments at each time interval was compared using a generalized linear model assuming a binomial distribution with a logit link function (PROC GENMOD in SAS).

\section{(g) Aphid response to headspace above leaflets from PLRV-infected plants and sham-inoculated plants}

Dual-choice tests for responses to headspace were conducted comparing PLRV-infected versus sham-inoculated plants, PLRV-infected versus uninfected controls, and sham-inoculated versus uninfected controls. Each comparison was replicated three times and aphid locations after $1 \mathrm{~h}$ were compared using a generalized linear model assuming a binomial distribution with a logit link function (PROC GENMOD in SAS). 
(h) Aphid emigration from headspace near virusinfected and virus-free potato plants

Thirty aphids were placed in the volatile test arena within the target area above a single leaflet. The number of aphids emigrating from the area directly above the leaflet was recorded every $10 \mathrm{~min}$ for $50 \mathrm{~min}$. At each observation, aphids that had emigrated from the target area were removed from the arena. Treatments were leaflets from PLRV-, PVX-, and PVY-infected plants, uninfected leaflets, and a no-leaflet control, and these were tested randomly to accumulate 10 replications. The number of aphids remaining on each treatment after $60 \mathrm{~min}$ was compared with analysis of variance (ANOVA) using a completely randomized design (PROC GLM in SAS). Planned contrasts compared aphids remaining above PLRV-infected leaflets versus those above each of the other four treatments.

\section{(i) Aphid response to volatiles collected from infected and virus-free potato plants}

Headspace volatiles from PLRV-infected and uninfected plants were trapped and tested for effects on $M$. persicae behaviour. To collect the volatiles, pairs of intact plants, with roots and the base of the plant tightly wrapped in aluminum foil, were enclosed in a glass collection chamber (Analytical Research Systems, Inc., Gainesville, FL). Humidified air, pre-filtered through activated carbon and Super-Q adsorbent resin (Alltech Associates, Deerfield, IL) was drawn through the chamber for $24 \mathrm{~h}$, at $300 \mathrm{ml} \mathrm{min}{ }^{-1}$, exiting through a trap containing $100 \mathrm{mg}$ of Super-Q. Immediately after volatile collection, the entire aerial portion of the plants was removed for determination of fresh and dry weights. Volatiles were eluted from the Super-Q trap with $400 \mu 1$ of HPLC-grade dichloromethane and applied to Whatman No. 2 filter paper leaflet models. Bioassays for aphid response to these models were identical to those used for the headspace above intact leaflets. One bioassay compared responses to volatiles from equal masses of PLRV-infected plants and uninfected plants ( $c a .1 .25$ leaf equivalents). Because volatile production is greater from the PLRV-infected plants (table 2), treatment concentrations were $360 \mathrm{ng}$ per model for uninfected plants and $710 \mathrm{ng}$ per model for PLRV-infected plants. A second bioassay compared volatiles from PLRVinfected and uninfected plants at the same concentration (360 ng per model). Quantification of volatiles was based on gas chromatography-mass spectrometry (GC-MS) as described in $\S 2(j)$. For each experiment, the mean number of aphids located over each treatment during the experiment was calculated for each replication and these mean values were compared using a generalized linear model assuming a binomial distribution with a logit link function (PROC GENMOD in SAS). There were 4-7 replications of each comparison.

\section{(j) Analysis of headspace volatiles from plants}

Volatiles were trapped for analysis from pairs of plants from each of the five treatments that were used in bioassays with aphids: PLRV-infected, PVY-infected, PVX-infected, shaminoculated, and uninfected controls, with no prior aphid feeding. Elutant from Super-Q traps was standardized to $400 \mu 1$ and a $1 \mu 1$ sample was injected onto a Hewlett-Packard 6890 gas chromatograph with a Hewlett-Packard 5973 Mass Selective Detector (Agilent Technologies, Palo Alto, CA). An external standard of terpenol was injected immediately before each extract sample. The column was a $30 \mathrm{~m} \times 0.2 \mathrm{~mm}$ i.d. HP- 1 , held at $40^{\circ} \mathrm{C}$ for $2 \mathrm{~min}$, then heated to $250^{\circ} \mathrm{C}$ at $10^{\circ} \mathrm{C} \min ^{-1}$ and held for 10 min. Peaks were identified based on the National Institute of
Standards and Technology library mass spectra and interpretation based on fragmentation and spectra of authentic standards when available. Dry weight/fresh weight ratios were similar for all treatments (data not shown) so quantities were calculated as nanograms per $100 \mathrm{~g}$ of above ground fresh plant. Separate volatile collections were made from at least three replicate pairs of plants in each treatment, providing a basis for statistical comparisons. Injections for each replicate were made in triplicate. Total volatile concentration in the headspace from the five treatments was compared using ANOVA followed by a least significant difference (LSD) means separation procedure (PROC GLM in SAS). Differences in the concentrations of individual components were not compared statistically, but standard errors were calculated. Non-overlapping standard errors were considered evidence of differences in concentrations.

\section{RESULTS}

(a) Aphid response to virus-infected and virus-free potato leaflets

Apterous $M$. persicae from our test clone preferentially settled onto leaflets from PLRV-infected plants versus leaflets from uninfected plants, and versus plants infected with either PVX or PVY (figure $1 a)(p=0.0002)$. From 25 to 86 (mean $=59.7$ ) of the 100 aphids in each trial were located on the leaflets of either treatment after $1 \mathrm{~h}$.

\section{(b) Aphid immigration to and emigration from virus-infected and virus-free potato leaflets}

Continuous observations of aphids in red light for $1 \mathrm{~h}$ detected higher rates of aphid immigration onto the PLRV-infected leaflets and lower rates of emigration (per cent per $10 \mathrm{~min}$ ) from these leaflets, producing the net greater number of aphids located on PLRV-infected leaflets than on uninfected leaflets (table 1).

\section{(c) Aphid response to headspace above virus-} infected and virus-free leaflets

Myzus persicae apterae responses to the headspace above leaflets was similar to responses when aphids could contact the leaflets (figure $1 b$, cf. figure $1 a$ ). More aphids were located in target areas above leaflets from plants infected by PLRV than above leaflets from uninfected plants, or above leaflets from plants infected with PVX and PVY ( $p=0.01$ for all comparisons). For all three comparisons, aphid preference for the headspace above PLRV-infected leaflets was significant for the duration of the test.

In a separate experiment, the number of $M$. persicae apterae was similar above leaflets from sham-inoculated plants and leaflets from uninfected controls with no prior aphid feeding $(49.0 \pm 2.4$ versus $51.0 \pm 2.49, p=0.463)$. More aphids were located above leaflets from PLRVinfected plants than above leaflets from either shaminoculated plants or uninfected controls (PLRV-infected $66.4 \pm 2.7$ versus sham-inoculated $33.6 \pm 2.7, p=0.0001$; PLRV-infected $69.0 \pm 3.8$ versus uninfected controls $30.7 \pm 3.7, p=0.0001)$.

In the bioassay to estimate emigration as affected by volatiles, emigration from the target area above leaflets from PLRV-infected plants was significantly less than emigration from any other treatment (ANOVA d.f. $=4,45$; $F=11.02 ; \quad p>F=0.0001 ; \quad$ all linear contrasts $p>F=0.0001$ ) (figure 2). After $50 \mathrm{~min}$, emigration from 
(a)

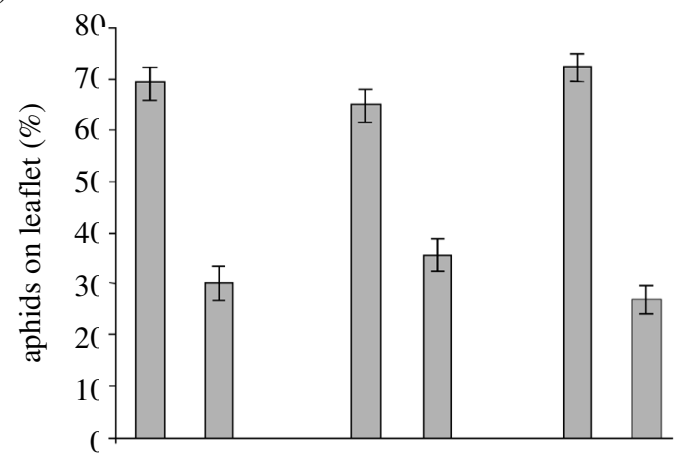

(b)

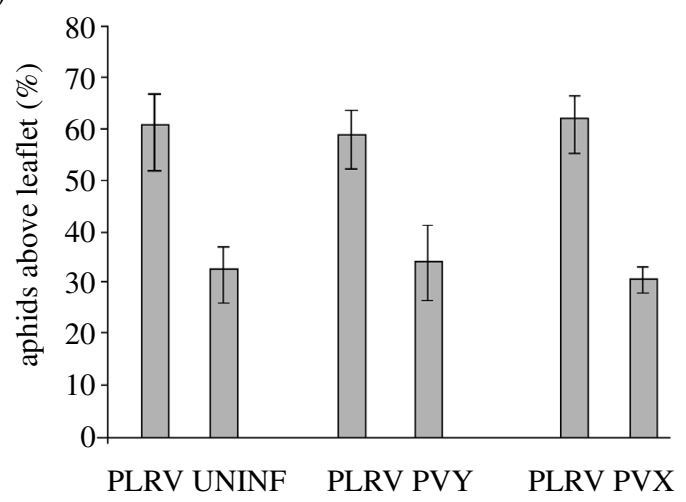

Figure 1. (a) Location of $M$. persicae apterae after $1 \mathrm{~h}$ in dual choice tests comparing potato leaflets from PLRV-infected plants with either uninfected plants (UNINF), PVY- or PVX-infected plants. Of the 100 aphids in each test, a mean of 59.7 responded (were located on one of the two treatments). Each pair of columns represents data from a single experiment. All comparisons were significant based on a generalized linear model assuming a binomial distribution with a logit link function (PLRV versus UNINF, $p=0002$; PLRV versus PVY, $p=0.0002$; PLRV versus PVX, $p=0.0001$.) Error bars are s.e.m. of the percent of aphids responding. (b) Location of $M$. persicae apterae after $1 \mathrm{~h}$ in dual choice tests above potato leaflets but in which aphids were prevented from contacting the leaflets, and comparing PLRV-infected with either uninfected plants (UNINF), PVY- or PVX-infected plants. All comparisons were significant based on a generalized linear model assuming a binomial distribution with a logit link function: (PLRV versus UNINF, $p=0.005$; PLRV versus PVY, $p=0.005$; PLRV versus PVX, $p=0.02$.). Error bars are s.e.m. of the percent of aphids responding.

no-leaf controls was similar to emigration from uninfected plants and appeared higher than from PVX- and PVYinfected plants, although these comparisons were not tested for significance.

\section{(d) Aphid response to volatiles collected from infected and virus-free potato plants}

More aphids were located in target areas above volatiles collected from the headspace of PLRV-infected plants than in target areas above volatiles collected from uninfected controls. This was true whether volatiles tested were standardized per fresh weight of potato plants from which volatiles had been collected $(10.0 \pm 0.9$ on PLRV

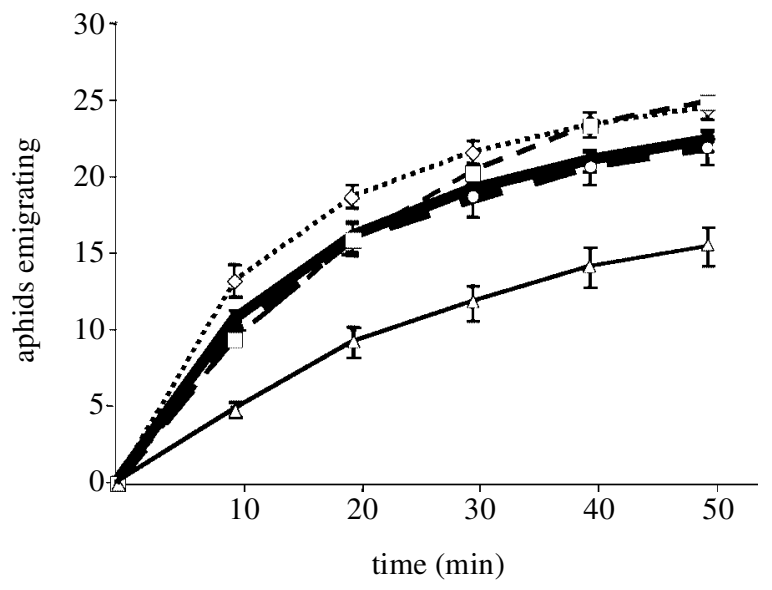

Figure 2. Cumulative aphids emigrating from target areas on screening directly above potato leaflets infected with PLRV, PVX, or PVY, uninfected leaflets, or a no-leaf control (30 aphids for each replication; $n=9)$. ANOVA for time $=50$ min, d.f. $4,45, F=11.02 ; p>F=0.0001$; planned contrast: PLRV-infected versus all others $F=40.27, p>F=0.0001$; Error bars are s.e.m. Diamonds, no-leaf control; squares, virus-free UNINF; open circles, PVX-infected; filled circles, PVY-infected; triangles, PLRV-infected.

versus $6.3 \pm 0.9$ on uninfected, $p=0.0001$ ) or whether the volatiles were presented at the same concentrations based on total ion chromatogram area from analysis of the volatiles $(13.9 \pm 0.7$ on PLRV versus $10.7 \pm 0.8$ on uninfected, $p=0.0001)$.

\section{(e) Headspace volatile analysis}

The headspace from PLRV-infected potatoes contained nearly double (1.9-fold) the concentration of total GC-MS-detectable components as uninfected controls, whereas PVY infection, PVX infection, or prior aphid feeding did not significantly change total volatile production (table 2). Although the same components were present in the headspace of plants from all treatments, there were differences in relative composition. Results are described here relative to the headspace from uninfected control plants. Based on non-overlapping standard errors, PLRV-infected plants produced higher concentrations of 14 of the 21 components detected, ranging from 1.6-fold ( $\beta$-sesquiphellandrene) to 5-fold (2-hexen-1-ol) over uninfected plants. PVX-infected plants produced higher concentrations of 2-hexen-1-ol (3-fold) and nonane (5-fold) and reduced concentrations of cobebene. PVX-infected plants produced higher concentrations of myrcene and reduced concentrations of cobebene. Sham-inoculated plants produced higher concentrations of nonanal, decanal, decane, $\beta$-sesquiphellandrene, and one unknown, and reduced concentrations of nonane, myrcene, pinene and germacrene D.

\section{DISCUSSION}

Potato plants (cv. Russet Burbank) infected with PLRV produce volatiles that attract and arrest $M$. persicae, a vector of PLRV. In choice tests, with and without contact with the leaf surface, more aphids were located on or near leaflets from PLRV-infected plants than on or near leaflets from plants infected with PVY, PVX, uninfected controls, 
Table 1. Movements during $1 \mathrm{~h}$ of 100 apterous $M$. persicae in test arenas containing PLRV-infected and uninfected potato leaflets.

(Data are mean results for $10 \mathrm{~min}$ intervals during four replicate $1 \mathrm{~h}$ observations. Significance values are based on generalized linear model assuming a Poisson distribution with a log link function. Abbreviations: mw, molecular weight; fw, fresh weight.)

\begin{tabular}{|c|c|c|c|c|}
\hline treatment & $\begin{array}{l}\text { aphids immigrating to } \\
\text { treatment per } 10 \mathrm{~min}\end{array}$ & $\begin{array}{l}\text { aphids emigrating from } \\
\text { treatment per } 10 \mathrm{~min}\end{array}$ & $\begin{array}{c}\% \text { of aphids emigrating } \\
\text { from treatment per } \\
10 \mathrm{~min}\end{array}$ & $\begin{array}{l}\text { net arrestment of aphids } \\
\text { on treatment per } 10 \mathrm{~min}\end{array}$ \\
\hline PLRV-infected & $18.6 \pm 1.9$ & $10.7 \pm 1.6$ & 57.7 & $7.9 \pm 1.1$ \\
\hline uninfected & $10.7 \pm 1.9$ & $8.4 \pm 1.2$ & 78.7 & $2.3 \pm 1.0$ \\
\hline$p$ & 0.0001 & n.s. & 0.0002 & 0.0005 \\
\hline
\end{tabular}

Table 2. Headspace volatiles from virus-infected and uninfected potato plants.

ng per $100 \mathrm{~g}$ (fresh weight) per $24 \mathrm{~h}^{\mathrm{b}}$

\begin{tabular}{|c|c|c|c|c|c|}
\hline component $^{\mathrm{a}}$ & uninfected controls & PLRV-infected & PVX-infected & PVY-infected & sham-inoculated $^{\mathrm{d}}$ \\
\hline 2-hexen-1-ol & $111 \pm 43$ & $755 \pm 311$ & $343 \pm 137$ & $283 \pm 150$ & $116 \pm 28$ \\
\hline heptanal & $599 \pm 330$ & $588 \pm 243$ & $289 \pm 102$ & $191 \pm 97$ & $392 \pm 141$ \\
\hline nonane & $133 \pm 61$ & $871 \pm 140$ & $694 \pm 87$ & $158 \pm 63$ & $32 \pm 1.08$ \\
\hline myrcene & $187 \pm 69$ & $593 \pm 198$ & $301 \pm 156$ & $640 \pm 231$ & $32 \pm 1.08$ \\
\hline limonene & $332 \pm 117$ & $661 \pm 120$ & $547 \pm 388$ & $411 \pm 178$ & $228 \pm 90.8$ \\
\hline pinene & $105 \pm 48$ & $226 \pm 14$ & $80 \pm 20$ & $50 \pm 17$ & $32 \pm 1.08$ \\
\hline nonanal & $134 \pm 61$ & $530 \pm 109$ & $290 \pm 177$ & $181 \pm 24$ & $460 \pm 179$ \\
\hline undecane & $113 \pm 60$ & $382 \pm 154$ & $328 \pm 186$ & $83 \pm 26$ & $264 \pm 48.4$ \\
\hline decanal & $195 \pm 106$ & $377 \pm 57$ & $192 \pm 78$ & $262 \pm 32$ & $968 \pm 91$ \\
\hline cobebene & $313 \pm 75$ & $379 \pm 117$ & $190 \pm 43$ & $146 \pm 37$ & $516 \pm 50$ \\
\hline cadinene & $156 \pm 40$ & $768 \pm 350$ & $182 \pm 35$ & $162 \pm 66$ & $192 \pm 49$ \\
\hline caryophyllene & $3796 \pm 651$ & $6931 \pm 1168$ & $2980 \pm 405$ & $2324 \pm 1091$ & $3948 \pm 1760$ \\
\hline$\alpha$-humulene & $294 \pm 174$ & $1082 \pm 248$ & $155 \pm 16$ & $540 \pm 264$ & $216 \pm 61$ \\
\hline $\begin{array}{l}\text { 7-11-dimethyl-3-methyl- } \\
\text { dodecatriene }\end{array}$ & & & & & \\
\hline $\begin{array}{l}\text { dodecatriene } \\
\text { germacrene D }\end{array}$ & $\begin{array}{l}1542 \pm 238 \\
3134 \pm 636\end{array}$ & $\begin{array}{l}3010 \pm 569 \\
3832 \pm 839\end{array}$ & $\begin{array}{l}1341 \pm 199 \\
2736 \pm 787\end{array}$ & $\begin{array}{l}14 / 9 \pm 795 \\
3235 \pm 1608\end{array}$ & $\begin{array}{l}2132 \pm 546 \\
1600 \pm 779\end{array}$ \\
\hline$\beta$-sesquiphellandrene & $332 \pm 54$ & $551 \pm 157$ & $355 \pm 80$ & $276 \pm 136$ & $624 \pm 163$ \\
\hline$\gamma$-elemene & $312 \pm 102$ & $431 \pm 185$ & $357 \pm 175$ & $387 \pm 192$ & $284 \pm 78$ \\
\hline longifolene & $251 \pm 48$ & $801 \pm 296$ & $251 \pm 84$ & $150 \pm 46$ & $148 \pm 69$ \\
\hline unknown (mw 204) & $489 \pm 79$ & $834 \pm 266$ & $558 \pm 107$ & $425 \pm 235$ & $1184 \pm 368$ \\
\hline unknown (mw 204) & $643 \pm 231$ & $985 \pm 119$ & $595 \pm 159$ & $350 \pm 183$ & $496 \pm 142$ \\
\hline total $^{c}$ & $12569 \pm 1711^{\mathrm{b}}$ & $24589 \pm 5009^{a}$ & $12749 \pm 2372^{\mathrm{b}}$ & $11729 \pm 3879^{b}$ & $13844 \pm 3653^{\mathrm{b}}$ \\
\hline
\end{tabular}

a In order of elution during gas chromatography.

${ }^{b}$ Values are the mean \pm s.e. of three or four replicate extractions from pairs of plants.

c Values with the same letter are not significantly different at the 0.05 level.

d Plants were inoculated with aviruliferous aphids more than four weeks prior to testing.

or sham-inoculated plants. This is the first report of volatile cues associated with viral infection in plants influencing the behaviour of a vector of that virus. Previous reports of aphid vector responses to infected hosts have implicated visual or gustatory mechanisms but have not identified the specific cues involved.

We conclude that the cues causing increased $M$. persicae settling on PLRV-infected plants are volatile because the responses occurred in the dark, precluding visual orientation, and occurred when aphids were prevented from contact with the leaflets, precluding tactile and gustatory cues. We conclude that the cues are PLRV-specific because aphids preferentially congregate over PLRVinfected leaflets as compared with PVX- or PVY-infected plants, plants sham-inoculated with aviruliferous aphids, or uninfected controls. The cues include attractants, as evidenced by higher rates of $M$. persicae immigration to
PLRV-infected leaflets than to uninfected leaflets (table 1). The cues include arrestants, as evidenced by reduced aphid emigration from the vicinity of the leaflets of PLRVinfected leaflets as compared with leaflets of plants infected with PVX or PVY, or uninfected controls. Headspace volatiles collected from PLRV-infected plants were arrestant, attractive, or both to the aphids as compared with volatiles from uninfected plants.

We have not identified specific arrestants or attractants for $M$. persicae in the headspace of PLRV-infected plants. Six headspace volatile components were elevated by PLRV infection but were not elevated by PVX or PVY infection or sham inoculation as compared with uninfected plants (limonene, pinene, cadinene, caryophyllene, $\alpha$-humulene, and 7-11-dimethyl-3-methyl dodecatriene). These components are candidate attractants or arrestants for M. persicae in this context. 2-Hexen-1-ol, heptanal, 
$\alpha$-pinene, caryophyllene generate electroantennogram (EAG) responses in $M$. persicae (Visser et al. 1996), but the two that have been tested for behavioural activity ( $\alpha$-pinene, $\beta$-caryophyllene) are inactive for $M$. persicae (Hori 1998). The activity of specific components and the possible importance of their ratios in the headspace of PLRV-infected plants remain to be determined.

The attraction or arrestment of $M$. persicae on PLRVinfected plants appears to be adaptive for the aphid because PLRV-infected plants are superior hosts for this insect (Castle \& Berger 1993). Myzus persicae attraction to or arrestment on infected plants could also explain the aggregated distribution of PLRV-infected plants in potato fields (Doncaster \& Gregory 1948; S. J. Castle \& P. H. Berger, unpublished data), which would not occur if aphids moved randomly between infected and uninfected plants (Ferriss \& Berger 1993). The implications of our findings for PLRV epidemiology will require further study, including tests with alate (winged) aphids, tests with viruliferous in addition to aviruliferous aphids and tests with plants at different stages in the progression of PLRV disease. Tests with different cultivars of potato and different aphid populations are also needed. Our results may apply uniquely to $M$. persicae in southern Idaho, from which the OUR clone was developed. In this region, $M$. persicae have been exposed to the extensively cultivated Russet Burbank and other closely related potato varieties, which harbour endemic PLRV infection (Nolte et al. 2000). Nonetheless, our results show that volatile emissions from virus-infected plants can affect an insect vector of the virus and suggest that the phenomenon can be examined in other aphidplant-virus associations.

The authors thank M. Klowden, A. Rodriguez, J. Tumlinson, $M$. Wiese and two anonymous reviewers for helpful comments on the manuscript. G. Chang, P. Duetting, D. Durr, S. Emmert, and C. Rutledge provided input throughout the experiments and comments on an earlier version of the manuscript. T. Mowry provided the M. persicae OUR clone to establish the research colony. W. Price provided statistical advice. The research was supported by Hatch project IDA01142 0177798 to S. E. This is MS \# 17601 of the Idaho Agricultural Experiment Station.

\section{REFERENCES}

Ajayi, O. \& Dewar, A. M. 1983 The effect of barley yellow dwarf virus on field populations of the cereal aphids, Sitobion avenae and Metopolophium dirhodum. Ann. Appl. Biol. 103, $1-11$.

Baker, P. F. 1960 Aphid behaviour on healthy and on yellow virus infected sugar beet. Ann. Appl. Biol. 48, 384-391.

Blua, M. J. \& Perring, T. M. 1992 Effects of zucchini yellow mosaic virus on colonization and feeding behaviour of Aphis gossypii (Homoptera: Aphididae) Alatae. Environ. Entomol. 21, 578-585.

Campbell, C. A. M., Pettersson, J., Pickett, J. A., Wadhams, L. J. \& Woodcock, C. M. 1993 Spring migration of damsonhop aphid, Phorodon humuli (Homoptera, Aphididae), and summer host plant-derived semiochemcials released on feeding. F. Chem. Ecol. 19, 1569-1576.

Castle, S. J. \& Berger, P. H. 1993 Rates of growth and increase of Myzus persicae on virus-infected potatoes according to type of virus-vector relationship. Entomol. Exp. Appl. 69, 51-60.

Castle, S. J., Mowry, T. M. \& Berger, P. H. 1998 Differential settling by Myzus persicae (Homoptera: Aphididae) on various virus infected host plants. Ann. Entomol. Soc. Am. 91, 661-667.

Costa, H. S., Brown, J. K. \& Byrne, D. N. 1991 Life history traits of the whitefly, Bemisia tabaci (Homoptera: Aleyrodidae) on six virus-infected or healthy plant species. Environ. Entomol. 20, 1102-1107.

de Bokx, J. A., \& Huttinga, H. 1981 Potato virus Y. In $C M I / A A B$ description of plant viruses 242. 354. Warwick, UK: Association of Applied Biologists.

Doncaster, J. P. \& Gregory, P. H. 1948 The spread of virus diseases in the potato crop. G.B. Agric. Res. Counc. Rep. Ser. 7, 1-189.

Eckel, R. V. W. \& Lampert, E. P. 1996 Relative attractiveness of tobacco etch virus-infected and healthy flue-cured tobacco plants to aphids. F. Econ. Entomol. 89, 1017-1027.

Fereres, A., Kampmeier, G. E. \& Irwin, M. E. 1999 Aphid attraction and preference for soybean and pepper plants infected with Potyviridae. Ann. Entomol. Soc. Am. 92, 542-548.

Ferriss, R. S. \& Berger, P. H. 1993 A stochastic simulation model of epidemics of arthropod-vectored plant viruses. Phytopathology 83, 1269-1278.

Harrison, B. D. 1984 Potato leafroll virus. In $C M I / A A B$ description of plant viruses. 291. Warwick, UK: Association of Applied Biologists.

Hodgson, C. J. 1981 Effects of infection with the cabbage black ringspot strain of turnip mosaic virus on turnip as a host to Myzus persicae and Brevicoryne brassicae. Ann. Appl. Biol. 98, 1-14.

Hori, M. 1998 Repellency of rosemary oil against Myzus persicae in a laboratory and screenhouse. F. Chem. Ecol. 24, 1425-1432.

Kennedy, J. S. 1951 Benefits to aphids from feeding on galled and virus-infected leaves. Nature 168, 825-826.

McElhany, P., Real, L. A. \& Power, A. G. 1995 Vector preference and disease dynamics: a study of barley yellow dwarf virus. Ecology 76, 444-457.

Macias, W. \& Mink, G. I. 1969 Preference of green peach aphids for virus-infected sugarbeet leaves. F. Econ. Entomol. $62,28-29$.

Nolte, P., Sandvol, L., Mowry, T., Stoltz, R., Olsen, N., Geary, B. D. C. \& Whitworth, J. 2000 Potato leaf roll and net necrosis. University of Idaho cooperative extension plant disease bulletin http://www.uidaho.edu/ag/plantdisease/pnniap.htm.

Nottingham, S. F., Hardie, J., Dawson, G. W., Hick, A. J., Pickett, J. A., Wadhams, L. J. \& Woodcock, C. M. 1991 Behavioural and electrophysiological responses of aphids to host and non-host plant volatiles. F. Chem. Ecol. 17, 12311242.

Pickett, J. A., Wadhams, L. J. \& Woodcock, C. M. 1992 The chemical ecology of aphids. A. Rev. Entomol. 37, 67-90.

Visser, J. H., Piron, P. G. M. \& Hardie, J. 1996 The aphids' peripheral perception of plant volatiles. Entomol. Exp. Appl. $80,35-38$. 